The University of Southern Mississippi

The Aquila Digital Community

Faculty Publications

$1-2014$

\title{
Culture of Lobotes surinamensis (Tripletail)
}

\author{
Eric Saillant \\ University of Southern Mississippi, Eric.Saillant@usm.edu \\ Jason T. Lemus \\ University of Southern Mississippi \\ James S. Franks \\ Center for Fisheries Research and Development
}

Follow this and additional works at: https://aquila.usm.edu/fac_pubs

Part of the Aquaculture and Fisheries Commons

\section{Recommended Citation}

Saillant, E., Lemus, J. T., Franks, J. S. (2014). Culture of Lobotes surinamensis (Tripletail). . Available at: https://aquila.usm.edu/fac_pubs/18337

This Article is brought to you for free and open access by The Aquila Digital Community. It has been accepted for inclusion in Faculty Publications by an authorized administrator of The Aquila Digital Community. For more information, please contact Joshua.Cromwell@usm.edu. 


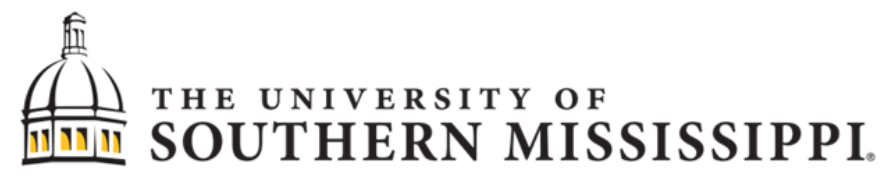

GULF COAST RESEARCH LABORATORY

\section{FINAL REPORT}

\section{CULTURE OF LOBOTES SURINAMENSIS (TRIPLETAIL)}

SUB-GRANT AGREEMENT S-11-M18A-USM-Tripletail-01 MISSISSIPPI DEPARTMENT OF MARINE RESOURCES TIDELANDS TRUST FUND PROGRAM

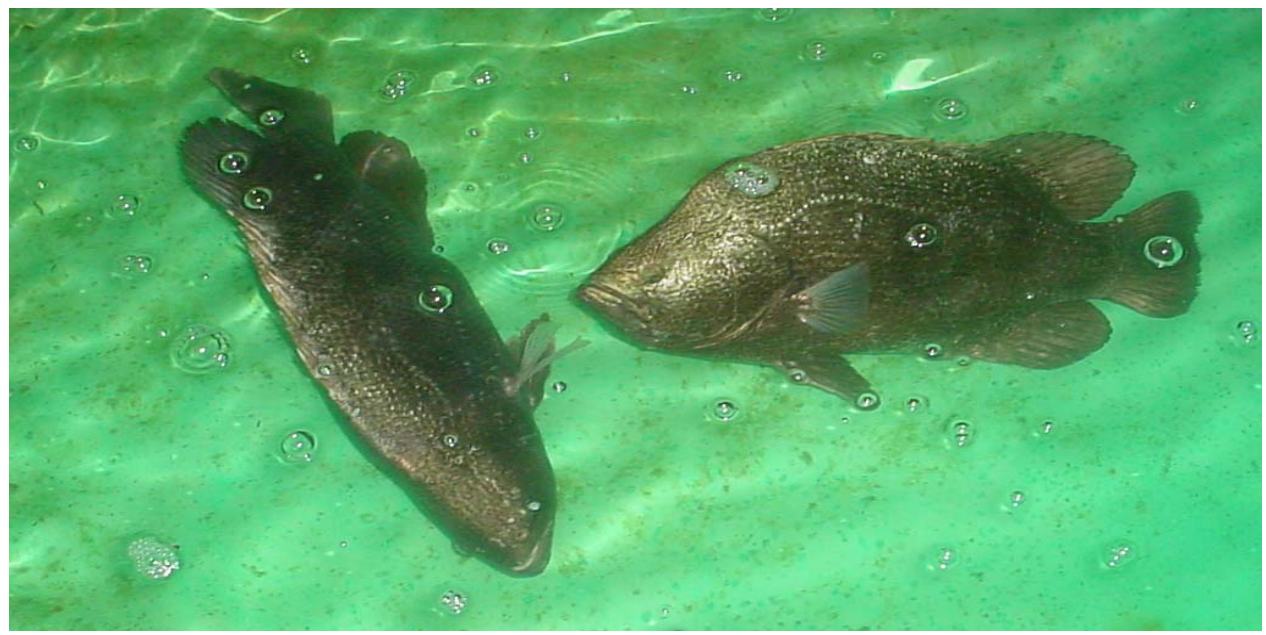

SUBMITTED TO

MISSISSIPPI DEPARTMENT OF MARINE RESOURCES BILOXI, MISSISSIPPI

SUBMITTED BY

GULF COAST RESEARCH LABORATORY THE UNIVERSITY OF SOUTHERN MISSISSIPPI OCEAN SPRINGS, MISSISSIPPI

PREPARED BY PRINCIPAL INVESTIGATORS

ERIC A. SAILLANT, PH.D. DEPARTMENT OF COASTAL SCIENCES

JASON T. LEMUS

DEPARTMENT OF COASTAL SCIENCES

JAMES S. FRANKS

CENTER FOR FISHERIES RESEARCH AND DEVELOPMENT

January 2014 


\section{CULTURE OF LOBOTES SURINAMENSIS (TRIPLETAIL)}

\section{Introduction}

The Tripletail, Lobotes surinamensis, is a pelagic fish found in tropical and sub-tropical waters of all oceans. Tripletails are often associated with floating debris and make frequent incursions in bays and estuaries where they are targeted by recreational fishermen. In Mississippi waters the species is typically present during the late spring and summer season that also correspond to the period of sexual maturation and spawning (Brown-Peterson and Franks 2001). Tripletail is appreciated as a gamefish but is also prized for its flesh of superior quality. The fast growth rate of juveniles in captivity documented by Franks et al. (2001) and the excellent quality of Tripletail flesh both contribute to the potential of this species for marine aquaculture. In addition, the production of cultured juveniles would be precious to develop a better understanding of the biology, early life history and habitat use of Tripletail larvae and juveniles, a topic largely undocumented to date, through experimental releases and controlled studies. The culture of tripletail thus supports the Tidelands Trust Fund Program through improved conservation of natural resources, potential enhancement of fisheries productivity and potential development of a new economic activity on the Gulf coast producing tripletail via aquaculture.

The Objective of this project was to initiate development of methods and techniques needed to spawn captive held tripletail broodfish and raise their offspring to evaluate their growth and development in captivity. In this report we will present the results of studies aiming to develop methods and protocols for captive spawning of tripletail and the first data obtained on the early development of tripletail larvae. A major issue that was encountered with tripletail broodstock development during the project lied in the difficulties associated with identifying the sex of adults caught in the wild and candidates for being incorporated in mating sets for spawning. This issue was addressed during the course of the project by examining the potential of a non-lethal method of hormonal sexing. The results of these preliminary investigations are presented in the third part of this report. All protocols used in the project were determined with the guidance of the Institutional Animal Care and Use Committee (IACUC) of the University of Southern Mississippi (USM IACUC protocol number 10100108).

\section{Development of captive spawning}

A primary challenge when developing aquaculture of new species such as the tripletail is the acquisition of the ability to control the reproduction of fish in captivity. The use of ripe gametes from wild-caught fish leads to unreliable and usually unsuccessful fertilization. In contrast, the development of captive spawning allows achieving a steady supply of high quality eggs as needed to develop larviculture protocols; captive spawning also allows developing off-season spawning using appropriate manipulation of temperature and photoperiod. Tripletail are rarely found ripe in near shore waters (Brown-Peterson and Franks 2001) and, when reproductively active fish are caught, gonad biopsies are very difficult to obtain with catheters so that the identification of the sex of captured animals often requires direct observation of the gonads after dissection. In addition, because of the solitary behavior of adult tripletails, the capture of several mature individuals within the same day is very challenging and this, along with the absence of reliable sexing method in the field effectively prevents the use of protocols involving induction of ovulation and strip-spawning of wild caught pre-mature fish that are routinely used to produce fertilized eggs in other species such as the red snapper (e.g. Minton et al. 1983). The only option 
to produce eggs for aquaculture therefore involves acclimating brooders to captivity and conditioning them for maturation and spawning using adequate photoperiod and temperature cycling (Mylonas and Zohar 2008). In many cases, hormonal disruptions do occur in captivity and successful maturation and spawning requires the use of hormonal therapies (Zohar and Mylonas 2001).

Previous attempts to condition Tripletail brooders to captivity led to a successful stripspawning event at GCRL in 2005 (J. Franks, J. Lemus and C.S. Lee, Unpublished results) and successful volitional tank spawning of acclimated brooders was also achieved following induction with LHRH, although with a low fertilization rate (J. Hyde, Personal Communication). The objectives of this project section were to investigate maturation and spawning of captiveheld broodfish. Hormonal induction followed by tank spawning was examined during three trials implemented during the course of the 2010 and 2011 reproduction seasons. Subsequently, the lack of identified males among our captive broodstock and among live fish brought to our facility prevented implementation of additional tank spawning trials. In the second part of the project we therefore examined an alternative protocol for spawning that involved strip-spawning of females acclimated and conditioned in captivity. This procedure involved developing the cryo-preservation of tripletail male gametes using sperm samples collected from wild caught fish. The latter was achieved through collaboration with Dr. Tiersch's Laboratory at the Agricultural Center of Louisiana State University.

\subsection{Materials and Methods}

\subsubsection{Broodstock collection and acclimation}

Fish were caught by hook and line and transported to facilities at the Thad Cochran Marine Aquaculture Center where they received routine prophylactic treatments including a 5 min freshwater bath followed by a 24 hour immersion in Praziquantel $(2.5-5 \mathrm{mg} / \mathrm{L})$ and a 1-month quarantine period when copper sulfate was maintained at or above $17.5 \mathrm{ppm}$ to ensure fish were free of Amyloodinium ocellatum. At the end of the quarantine period, fish were individually tagged with Passive Integrated Transponder (PIT) tags and brought to spawning tanks located in the visitor's center of the Thad Cochrane Marine Aquaculture Center.

\subsubsection{Fish husbandry and conditioning for maturation}

Fish were maintained in 10-ft diameter circular spawning tanks provided recirculating water and mechanical and biological filtration. Each tank was connected to an individual filtration system that included temperature control (1.5 hp heat pump, Aqualogic), mechanical (sand filtration Triton II TR 60, Pentair) and biological (Fluidized bed sand filter, Aquaculture Systems Technologies, LA) filtration, protein skimming (RK2 systems), ozonation (1,000 mg, RK2 systems), and crushed coral substrate-based filtration. Daylight was provided with two 32-watt compact fluorescent bulbs (Aquadyne) providing a cumulative intensity of approximately 120 lux. An additional 13-watt bulb was used to provide a progressive increase/decrease of light intensity at sunrise and sunset.

Tanks were equipped with a surface egg collector connected to the side of the tank. This method collects surface water which allows separating floating particles from sinking particles. This collector thus selectively collects eggs with high floatability, including fertilized eggs, while 
most dead and unfertilized eggs, which show reduced floatability, exit the tank through the bottom drain. Eggs concentrated in the surface collector were maintained in suspension by gentle aeration until harvest. A mesh bag was attached to the bottom-center drain discharge located within a sump tank in order to allow collecting and counting sinking eggs.

Photoperiod and temperature simulated the natural cycle of variation in offshore Mississippi waters during the winter and spring maturation periods. When temperature reached summer conditions, conducive of spawning, the photoperiod and temperature were kept constant until the spawning trial could be scheduled. Temperature, salinity and dissolved oxygen levels were checked daily. Water quality parameters including $\mathrm{pH}$, total ammonia, nitrite, and nitrate levels were checked weekly and maintained $<1 \mathrm{mg} . \mathrm{L}^{-1}$ for total ammonia nitrogen, $<2 \mathrm{mg} . \mathrm{L}^{-1}$ for nitrite, $<100 \mathrm{mg}$. $\mathrm{L}^{-1}$ for nitrates and between 7.9-8.2 for $\mathrm{pH}$. Fish were fed a diet composed of fish, shrimp and squid at a 2:1:1 ratio, three times per week to satiation (which amounted to 1 to $4 \%$ BW depending on the temperature). The diet was supplemented with a multivitamin complex once per week during the spawning season.

\subsubsection{Hormonal induction and spawning trials}

Fish were anaesthesized by immersion in a 100ppm MS-222 bath and gonadal biopsies were obtained from females using a Frydman memory catheter (CCD International). The oocytes collected on females were fixed in a desopacifying fixative (Ethanol Formalin Acetic acid, EFA 6:3:1) and observed at $40 \mathrm{x}$ magnification under a dissecting microscope to determine oocyte size and pre-maturation status at the time of hormonal induction. The acquisition of an ovarian biopsy during catheterization allowed identifying the sex of the females. Because biopsy samples are very difficult to obtain in tripletail, fish where no biopsy could be obtained were potentially either males or females (i.e. phenotypic sex was unknown). Ripe males in most other species can be sexed during the spawning season by pressing the flanks of the animal and observing emission of milt through the genital pore but unfortunately in our experience tripletail males usually do not release milt even when ripe (J. Franks, Unpublished Results).

Experiment 1 - This experiment was conducted in late summer 2010. Ovaplant ${ }^{\circledR}$ (Syndel) hormonal implants delivering a Salmon Gonadotropin (sGnRHa)- Releasing Hormone analogue

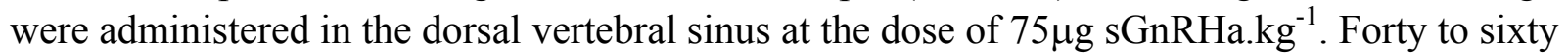
percent of the sGnRHa dose is released in the bloodstream during the first 24 hours post induction and the remainder over the next 7 to 21 days. Six fish were administered implants in a first trial implemented on September 7 2010. Two putative females and one unsexed fish (possible male) with implants were allocated to each of two spawning tanks for monitoring of spawning activity (Table 1). On October 8, the four fish present in tank 1 were examined and two females and one putative male were administered implants and returned to the tank for spawning. 
Table 1. Size and maturation status of individual Lobotes surinamensis broodstock implanted with Salmon Gonadotropin Releasing Hormone analogue implants (Ovaplant). F: female, M: Male, U: Undetermined, Vg: vitellogenic oocytes (mean oocyte diameter in $\mu \mathrm{m}$ ), PG: primary growth, AT: Atresia, +: implant ( $\left.75 \mu \mathrm{g} \cdot \mathrm{kg}^{-1} \mathrm{~s}-\mathrm{GNRHa}\right)$, - no implant.

\begin{tabular}{|c|c|c|c|c|c|c|c|}
\hline Date & Tank\# & Tag \# & TL $(\mathrm{cm})$ & Weight (kg) & Sex & Maturation status & Implant \\
\hline 7-Sep & 1 & 87000 & 620 & 7.1 & $\mathrm{~F}$ & $\operatorname{Vg}(584)$ & \\
\hline 7-Sep & 1 & 73561 & 680 & 8.4 & $\mathrm{~F}$ & $\operatorname{Vg}(438)$ & \\
\hline 7-Sep & $1^{n}$ & 02725 & 620 & 6.57 & U & $-*$ & \\
\hline 7-Sep & $1^{\prime \prime}$ & 07443 & 645 & 8.05 & $\mathrm{~F}$ & $\operatorname{Vg}(450)$ & \\
\hline 7-Sep & 4 & 18898 & 585 & 5.56 & $\mathrm{~F}$ & $-\dagger$ & \\
\hline 7-Sep & 4 & 97048 & 640 & 8.58 & $\mathrm{~F}$ & $\operatorname{Vg}(497)$ & \\
\hline 7-Sep & 4 & 40643 & 620 & 7.3 & $\mathrm{~F}$ & $\operatorname{Vg}(526)$ & \\
\hline 7-Sep & 4 & 99383 & 690 & 5.75 & $\mathrm{~F}$ & PG & \\
\hline 7-Sep & 4 & 46124 & 605 & 3.8 & $\mathrm{M}$ & NA & - \\
\hline 7-Sep & 4 & 18959 & 580 & 3.73 & $\mathrm{~F}$ & $\operatorname{Vg}(568)$ & \\
\hline 8-Oct & 1 & 73561 & 680 & 8.73 & $\mathrm{~F}$ & AT & \\
\hline 8-Oct & 1 & 87000 & 620 & 6.61 & $\mathrm{~F}$ & $-*$ & $t$ \\
\hline 8-Oct & $1^{\prime}$ & 07443 & 645 & 8.05 & $\mathrm{~F}$ & $\operatorname{Vg}(434)$ & - \\
\hline 8-Oct & $1^{\prime \prime}$ & 02725 & 620 & 6.42 & M & NA & \\
\hline
\end{tabular}

* Catheter could not be inserted into gonoduct, $\uparrow$ Measurements non available

Experiment 2 - This experiment was conducted in September 2011. Implants delivering a super-active cleavage-resistant GnRH agonist ([D-Ala6, Pro9NEt]-GnRH), that has been shown to be highly effective in inducing LH release (Zohar et al. 1989, Zohar et al. 1990) and oocyte maturation (OM) in fish (Mylonas et al. 1995, Mylonas et al. 1998b) were provided by Dr. Zohar (University of Maryland) and administered to the 8 fish present in the spawning tank on September 27 at a dosage of $75 \mathrm{ug} \cdot \mathrm{kg}^{-1}$ (Table 2). These delivery systems release GnRHa into the blood for periods of 2-6 weeks (Mylonas et al. 1995; Zohar 1996). The fish were returned to the spawning tank for monitoring of spawning activity.

In both experiments 1 and 2, spawning activity was monitored by checking for the presence of eggs in the side collector of the tank and in a collecting mesh set at the outflow of the center drain of the tanks. The number of eggs produced during spawning events was estimated volumetrically, and the fertilization rate was estimated by directly counting developing embryos and unfertilized eggs under a dissecting microscope. 
Table 2. Size and maturation status of individual Lobotes surinamensis broodstock implanted with a slow release [D-Ala6, Pro9NEt]-GnRHa implant (75 $\mu$ g GNRHa.kg $\left.{ }^{-1}\right)$. F: female, M: Male, U: Undetermined, Vg: vitellogenic oocytes (maximum oocyte diameter in $\mu \mathrm{m}$ ), PG: primary growth (maximum oocyte diameter in $\mu \mathrm{m}$ ).

\begin{tabular}{|rrrrr|}
\hline Tag \# & TL(cm) & Weight $(\mathrm{kg})$ & Sex & Maturation status \\
\hline 14702 & 62 & 5.22 & $\mathrm{~F}$ & $\mathrm{PG}(<80)$ \\
46124 & 65 & 6.12 & $\mathrm{U}$ & $-*$ \\
40643 & 67 & 6.57 & $\mathrm{~F}$ & $\mathrm{Vg}(600)$ \\
15038 & 56 & 2.97 & $\mathrm{U}$ & $-*$ \\
18959 & 59 & 5.96 & $\mathrm{~F}$ & $-*$ \\
99383 & 70.5 & 8.89 & $\mathrm{~F}$ & $\mathrm{Vg}(500)$ \\
97048 & 66.5 & 8.48 & $\mathrm{U}$ & $\mathrm{Sp}$ \\
94387 & 65 & 8.32 & $\mathrm{~F}$ & $\mathrm{Vg}(400)$ \\
\hline
\end{tabular}

* Catheter could not be inserted into gonoduct

Experiment 3 - This experiment was conducted in late summer 2013. At that time there was no identified male among the broodstock, and, in consequence, we did evaluate response to a direct gonadotropin induction of the females with the prospect of performing strip-spawning of ovulated eggs and in-vitro fertilization with cryo-preserved sperm if ovulation was achieved with the treatment.

Two trials were implemented. Four of the eight available fish were administered an intramuscular injection of chorionic gonadotropin (hCG) at a dose of $1,100 \mathrm{IU} / \mathrm{kg}$ on October 08 and transferred to four 400-1 aquarium for observation. Monitoring of oocyte maturation and ovulation proceeded from 24-h to 36-h post induction and consisted in observing the behavior of the females, the degree of inflation of their flanks and of dilatation of their genital papilla, and examination of the maturation stage of oocytes obtained in ovarian biopsies.

A second trial was performed on October 15 using the same protocol as in the October 08 trial except that after 36 hours post administration of the hCG treatment, a resolving induction was performed using $0.5 \mathrm{ml}$ Ovaprim ${ }^{\circledR}$. Ovaprim contains the same LHRH analog as the ovaplant implant used in experiment 1 but also contains an antidopaminergic compounds that counteract stress inhibitions that could impact response to the LHRH. The status of individual broodfish fish at the time of induction is presented for both trials in Table 3. 
Table 3. Size and maturation status at the induction date of individual Lobotes surinamensis broodstock administered a hCG treatment or a combination of hCG and Ovaprim (see text for details). F: female, M: Male, U: Undetermined, Vg: vitellogenic oocytes (maximum oocyte diameter in $\mu \mathrm{m})$, PG: primary growth.

\begin{tabular}{|c|c|c|c|c|c|}
\hline Date & Tag \# & $\mathrm{TL}(\mathrm{cm})$ & Weight (kg) & Sex & Maturation status \\
\hline $8-$ Oct & 5038 & 64 & 6.5 & $\mathrm{U}$ & $-*$ \\
\hline 8-Oct & 6124 & NA & NA & $\mathrm{F}$ & $\mathrm{Vg}(400)$ \\
\hline 8-Oct & 9383 & NA & 10.9 & $\mathrm{~F}$ & $\mathrm{PG}$ \\
\hline $8-O c t$ & 7515 & 64 & 5.8 & $\mathrm{U}$ & $-*$ \\
\hline 15-Oct & 4387 & 69 & 8 & $\mathrm{~F}$ & VG (500) \\
\hline $15-O c t$ & 4702 & 66 & 6.15 & $\mathrm{~F}$ & $P G$ \\
\hline $15-$ Oct & 8229 & 69 & 8.34 & $\mathrm{~F}$ & VG (450) \\
\hline $15-$ Oct & 3355 & 66.5 & 6.45 & $\mathrm{~F}$ & $-*$ \\
\hline
\end{tabular}

* Catheter could not be inserted into gonoduct

\subsubsection{Evaluation of protocols for cryopreservation of tripletail sperm}

This project section was developed in a collaborative effort with Drs. Hu and Tiersch at the Agricultural Center of Louisiana State University (LSU-AC). The goal of this section of the project was to establish a cryopreservation protocol for tripletail and eventually to accumulate enough frozen samples for artificial spawning trials conducted at the end of summer 2013 (experiment 3 described in section 1.1.3). Collection trips began during the 2012 season but no ripe male was caught. In 2013, fishing trips to catch adult ripe males and preserve sperm samples were conducted on 07/01, 07/19,07/31, 08/01, 08/08,08/11, and 09/03.

Fish were kept on ice from the time of capture and brought to GCRL or LSU-AC for processing. Testes were dissected from the general cavity and sperm was extracted from the testis tissue by pipetting, immediately diluted in HBSS-200 mosm, and kept at $4{ }^{\circ} \mathrm{C}$ until freezing.

In July 2013, preliminary freezing test were performed at GCRL with a portable freezing device (CryoKit v1.0) developed by Drs Tiersch and Hu. From August to September, testes were brought to LSU-AC for processing. The cryopreservation was performed with both a programmable freezer and a modified version of the portable freezing device (CryoKit v2.0). Sperm was stored in $0.5-\mathrm{ml}$ French straws with a loading concentration of $10^{8}$ spermatozoa $\mathrm{ml}^{-1}$.

\subsection{Results}

The inability to reliably identify the sex of live tripletail collected during the spawning season was a major difficulty during broodstock establishment and all spawning trials. Reliable biopsy samples could only be obtained from some of the females and there was no method to positively identify males because mature males did not release sperm following abdominal massage. This difficulty was the impetus for the third part of this report which aims to examine non-lethal sexing methods for tripletail candidate brooders. 
No spontaneous spawning (i.e. without administration of hormonal treatments) of broodstock held in spawning tanks was recorded at any time during the whole duration of the project that encompassed 4 spawning seasons.

\subsubsection{Hormonal induction trials}

\section{Experiment 1}

Eight of the fish used in spawning events were putative females and the remaining 2 fish were unidentified and presumably of high likelihood to be males. The six fish administered implants on September 07 included 4 females (confirmed with biopsy samples) and 2 unidentified fish. Two treated females and one unidentified fish were returned to one of the two spawning tanks (tank 1) along with a control female that received no implant. The other two treated females, the second unidentified fish and the remaining fish not treated with implants were allocated to the second tank (tank 4, Table 1).

A first egg release was observed on September 09 but could not be quantified. Large egg releases were recorded in both spawning tanks on September 10 ( $>48 \mathrm{~h}$ post induction). The release in tank 1 included an estimated 715,000 eggs with a fertilization rate of $9.8 \%$. The egg release in tank 4 gave a similar number of eggs $(764,000)$ none fertilized. Additional egg releases were observed on September 11 and 12 in both tanks but were smaller (average 75,000 eggs per day $\mathrm{x}$ tank) and non-fertile (Table 4).

Two females and one unidentified fish were implanted on October 18. Multiple egg releases were recorded following this second induction trial but no fertilized eggs were produced (Table 4).

At the end of the second trial, broodfish were allocated to 2 tanks and kept for trials during the 2011 spawning season. Unfortunately, all the fish present in one of the two tanks, including 2 of the 3 putative males (unidentified fish), were lost due to a technical failure in spring 2011. This mortality event allowed determining the sex of the unidentified fish which were confirmed as males. Two new fish were added to the broodstock (unidentified sex). A total of 8 broodfish were available for spawning in 2011 (experiment 2 described below) including 3 fish of undetermined sex.

\section{Experiment 2}

At the time of induction, one female was undeveloped with oocytes less than $80 \mu \mathrm{m}$ in diameter and 3 other females showed advanced stages of vitellogenesis with maximum oocytes diameters between 400 and $600 \mu \mathrm{m}$. The fifth fish that was examined released sperm during catheterization which allowed sexing this fish as a male. The maturation status of the remaining 3 fish could not be determined because no biopsy could be obtained during catheterization. Two egg releases were observed post induction with LHRH implants. The first one was recorded on 09/29 between 3am and 8am (40-45h post administration of the implants) and included an estimated 2.1 M eggs, none fertilized. The second was recorded on Friday 09/30 in the afternoon (between $11 \mathrm{am}$ and $3 \mathrm{pm}, 72-75 \mathrm{~h}$ post administration of the implants) with another estimated $2 \mathrm{M}$ eggs none fertilized (Table 4). 
Table 4. Summary of the results of hormone-induced tank spawning trials performed in 2010 and 2011

\begin{tabular}{|c|c|c|c|c|c|}
\hline Induction date & $\begin{array}{l}\text { Hormonal } \\
\text { induction }\end{array}$ & $\begin{array}{l}\text { Egg release } \\
\text { date }\end{array}$ & Tank & \# eggs & $\begin{array}{l}\text { Fertilization } \\
\text { rate }\end{array}$ \\
\hline \multirow[t]{8}{*}{ 09/07/2010 } & \multirow{8}{*}{$\begin{array}{l}\text { Ovaplant }{ }^{\circledR} \\
(\mathrm{s}-\mathrm{GnRH}), \\
75 \mu \mathrm{g} / \mathrm{kg}\end{array}$} & $09 / 09 / 2010$ & 1 & NA & $0 \%$ \\
\hline & & $09 / 09 / 2010$ & 4 & NA & $0 \%$ \\
\hline & & $09 / 10 / 2010$ & 1 & 715,000 & $9.8 \%$ \\
\hline & & $09 / 10 / 2010$ & 4 & 764,000 & $0 \%$ \\
\hline & & $09 / 11 / 2010$ & 1 & 57,500 & $0 \%$ \\
\hline & & $09 / 11 / 2010$ & 4 & 173,500 & $0 \%$ \\
\hline & & $09 / 12 / 2010$ & 1 & 50,000 & $0 \%$ \\
\hline & & $09 / 12 / 2010$ & 4 & 20,000 & $0 \%$ \\
\hline \multirow[t]{3}{*}{ 10/08/2011 } & \multirow{3}{*}{$\begin{array}{l}\text { Ovaplant }{ }^{\circledR} \\
\text { (s-GnRH), } \\
75 \mu \mathrm{g} / \mathrm{kg}\end{array}$} & $10 / 11 / 2010$ & 1 & 755,000 & $0 \%$ \\
\hline & & $10 / 12 / 2010$ & 1 & 72,500 & $0 \%$ \\
\hline & & $10 / 13 / 2010$ & 1 & 75,000 & $0 \%$ \\
\hline \multirow[t]{2}{*}{$09 / 27 / 2011$} & \multirow{2}{*}{$\begin{array}{l}\text { [D-Ala6, } \\
\text { Pro9NEt]-GnRH, } \\
\text { slow release } \\
75 \mu \mathrm{g} / \mathrm{kg}\end{array}$} & $09 / 29 / 2011$ & 1 & $2,100,000$ & $0 \%$ \\
\hline & & $09 / 30 / 2011$ & 1 & $2,000,000$ & $0 \%$ \\
\hline
\end{tabular}

One of the unidentified fish died in October and was sexed as male. Fish were kept in tanks and conditioned for an additional year. An additional tripletail specimen held in the fish health facility was included in the broodstock in fall 2012, but its sex was unknown. Because there was no fish positively identified as male present in the spawning tank in 2012 and 2013, and no fertilized eggs had been produced during the 2011 trial, the project team decided to proceed with strip-spawning of captive females following hormonal induction with gonadotropin. The procedure involved using preserved tripletail sperm and collaboration with Dr. Tiersch's Laboratory at LSU-AC was initiated to develop methods to cryo-preserve tripletail sperm and accumulate sperm samples needed to fertilize ovulated eggs from our captive females if ovulation was successfully induced with our treatment. No cryopreserved sperm samples were available to attempt artificial fertilization in 2012. Spawning trial were therefore postponed until fall 2013 as outlined in intermediate progress reports.

\section{Experiment 3}

Two of the 4 females induced on October 08 had oocytes at late stages of vitellogenesis (400 to $500 \mathrm{um}$ ) although the vitellus did not show clearly defined oil globules suggesting a relatively early post-vitellogenic status. The remaining females had oocytes in primary growth $(<80 \mathrm{um}$ in diameter) or biopsy samples could not be obtained. On October 15, the four females that were induced included one female with relatively abundant large oocytes (500um), a second female with a few large oocytes ( $450 \mathrm{um}$ ) and a majority of small oocytes, and a female with primary growth oocytes. The biopsy could not be obtained for the last female. Similar to the October 08 trial, larger oocytes showed undefined lipid globules suggestive of early post-vitellogenic status.

Females were induced using hCG on October 08 or using a combination of hCG and Ovaprim (October 15 trial). None of the female ovulated, and no visible change in oocyte maturation status was observed during the monitoring period except for some isolated late signs 
of hydration of a few oocytes in the most advanced females induced on October 15. Even in the latter case, most of the oocytes remained at the pre-induction stage.

\subsubsection{Development of a cryo-preservation method for tripletail}

The sperm of 16 wild-caught males was cryo-preserved. Nine of the sperm samples (253 straws total) had motilities greater than $5-10 \%$ which is sufficient for fertilization trials. Another 349 straws were obtained from the remaining 6 males but motility was very low $(<1 \%)$.

A summary of the number of sperm samples frozen during the study, and of motility data obtained prior to freezing and after freezing and thawing for each sample is reported in Table 5.

Table 5. Characteristics of sperm samples frozen during the project and available for spawning trials

\begin{tabular}{|l|l|l|l|l|}
\hline Date & Male & $\begin{array}{l}\text { Motility } \\
(\%)\end{array}$ & $\begin{array}{l}\text { Post-thaw } \\
\text { motility } \\
(\%)\end{array}$ & $\begin{array}{l}\text { Number } \\
\text { of straws }\end{array}$ \\
\hline $7 / 2 / 2013$ & 3 & $10-15$ & $1-10$ & 4 \\
\hline & 5 & $30-40$ & $15-25$ & 13 \\
\hline $8 / 11 / 2013$ & 1 & $5-10$ & $0-1$ & 13 \\
\hline & 3 & $3-8$ & $1-3$ & 17 \\
\hline $8 / 12 / 2013$ & 1 & $15-25$ & $5-10$ & 43 \\
\cline { 3 - 5 } & & & $15-20$ & 8 \\
\cline { 3 - 5 } & 2 & $10-20$ & $20-30$ & 14 \\
\hline & 3 & $5-15$ & $1-5$ & 40 \\
\hline & & & $1-3$ & 19 \\
\hline $9 / 3 / 2013$ & 1 & $10-20$ & 0 & 81 \\
\hline & 5 & $40-50$ & $0-1$ & 143 \\
\hline & 6 & $40-50$ & $0-1$ & 65 \\
\hline & 8 & $30-40$ & $5-10$ & 17 \\
\hline & 9 & $20-30$ & $10-15$ & 60 \\
\hline & 12 & $50-60$ & $10-15$ & 10 \\
\hline & 13 & $30-40$ & $5-10$ & 11 \\
\hline & 15 & $30-40$ & $5-10$ & 37 \\
\hline
\end{tabular}

Total number of males: 16. Total number of straws: 602 .

The recommended protocol for cryo-preservation of tripletail sperm based on the preliminary trials implemented at LSU-AC is summarized below:

Sperm processing steps:

1. Separate testes from fat tissues, dry and clean the testes surface;

2. Place the testes on Petridish and cut into segments;

3. Squeeze each segment from one end to the other and quickly dilute with HBSS200 then transfer to $1.5 \mathrm{ml}$ tubes;

4. After all segments are squeezed, count the concentration of each tube;

5. Adjust the concentration to $2 \times 10^{8} \cdot \mathrm{ml}^{-1}$;

6. Prepare the same volume of $20 \%$ DMSO in HBSS200; 
7. $1: 1$ ratio mix the $20 \%$ DMSO and $2 \cdot 10^{8} \cdot \mathrm{ml}^{-1}$ samples, then equilibrate for $15-25$ $\min$;

8. $\quad$ Freeze

Two freezing protocols were used successfully:

1. Freezing with programmable freezer at cooling rate $30^{\circ} \mathrm{C} / \mathrm{min}$ from $4^{\circ} \mathrm{C}$ to $-80^{\circ} \mathrm{C}$;

2. Freezing with CryoKit v2.0 using combination of " $0.5 \mathrm{ml}$ straw, single layer, hollow boat" (see Manual for Freezing Using CryoKit (v2.0) Table 1)

The fertilization potential of the obtained sperm samples could not be evaluated because of the lack of ovulation of females following induction with chorionic gonadotropin (see result section 1.2.1 experiment 3 above). Sperm samples are being kept at LSU-AC and will be available if opportunities to strip-spawn tripletail females presents in the future.

\subsection{Discussion and conclusions}

In this work we monitored maturation and spawning of captive tripletail broodstock during four spawning seasons. During the 2010 and 2011 spawning seasons our broodstock included individuals of both sexes with some of the females reaching advanced stages of oogenesis in spawning tanks. Spawning did not occur spontaneously at any time during the monitoring period, indicating that, although maturation of gametes appeared to be initiated in Tripletail captive broodstocks using the photothermal conditioning that we employed, some inhibition of final maturation and/or spawning occurred. Failure of captive broodfish to mature and/or to spawn spontaneously in tanks is relatively common in cultured fish and has often been linked to a dysfunctional Brain-Pituitary Axis (Zohar and Mylonas 2001). The most common disruption of gametogenesis in captive-held broodfish is failure to undergo final maturation (spermiation in males and final oocyte maturation and ovulation in females) and/or spawning. Results of the present study also indicate that disruptions occur at early stages of the gametogenesis process as some of the large females of reproductive size only displayed oocytes in primary growth or at early stages of vitellogenesis $(<80 \mu \mathrm{m}$ in diameter). We therefore attempted to induce maturation and spawning using gonadotropin releasing hormone implants as this approach has been show to overcome endocrine disruptions in several cultured species (Zohar and Mylonas 2001; Mylonas and Zohar 2008).

Induction of final maturation and spawning using LHRH implants (Ovaplant in 2010 and Dr. Zohar's implants in 2011) was attempted during three trials conducted in 2010 and 2011. The results of these trials are encouraging relative to the hormonal induction of ovulation in females in that ovulation and egg release of our captive females was achieved in all 3 trials with high fecundity (up to $2.1 \mathrm{M}$ eggs released per spawning date and a total of $4.1 \mathrm{M}$ eggs in the induction trial performed in 2011). Unfortunately, most of the spawns were unfertile. This result may reflect in part the low number of males available in our broodstock throughout the study. Tripletails are difficult to capture in large numbers and the absence of a reliable technique to identify positively males in the field was a challenge when developing our broodstock. The total lack of fertilization in most trials in the presence of males (sexed post-mortem in some cases), also indicates that our males did not participate to spawning events following hormonal induction. While we could not assess directly the maturation status of males due to difficulties to observe spermiation and evaluate quantitatively spermatogenesis in male tripletail, these results 
suggest that major inhibitions of the male sexual cycle do occur in captivity. Such inhibitions have been reported in other marine species including red snapper broodstocks in our laboratory (Bardon et al. In Press; Saillant and Bardon Unpublished results). Further investigations manipulating the density and sex ratio among broodstock would be warranted to determine if spermiation and spawning of males (as measured by the fertility of spawn) could be improved. We do note that, although the disruptions could be temporally overcome in females with egg releases during the first 2 to 3 days post induction, the treatment was only effective for a brief period of time and spawning activity stopped after a couple of days suggesting that the disruption was still active. The fertilization data also suggest that the treatment may have been even less effective in males and/or that inhibitions are stronger in the male sex.

In some fish species, stress hormones such as dopamine act on the brain and inhibit the action of the gonadotropin releasing hormone produced by the brain (and used in our induction protocol) to regulate maturation and spawning. A more effective hormonal therapy may therefore include antidopaminergic conpounds such as domperidone used in conjunction with GnRH in Ovaprim (® Syndel) and that acts to block those inhibitions (see e.g. Wang et al., 2009). Finally, we note that, in 2013, when no male was present among the broodstock, the spawning trials were largely ineffective. While some females had fully grown oocytes $(>400 \mu)$, their prematuration status may have been less advanced than in previous years due to the lack of interaction with males which would explain the lack of response to the gonadotropin treatments. This result highlights the potential importance of maintaining broodstocks of both sexes to ensure maturation of females in captivity and response to hormonal induction if needed.

In this work the development of a protocol for sperm cryopreservation was initiated thanks to the collaboration of Drs. Tiersch and Hu at LSU-AC. The preliminary trials were successful at cryo-preserving sperm samples and a large number of straws could be preserved and were available for use in spawning trials. Unfortunately, the sperm samples could not be tested in fertilization trials due to the lack of ovulation following gonadotropin induction but the motility was preserved post-freezing and thawing which suggests that fertilization potential was likely maintained during the process. The protocol developed in this project section can serve as a platform for further development of cryo-preservation in tripletail and applications to captive spawning in this species. A difficulty that was encountered during cryo-preservation trials was linked to the paucity of ripe males among captured fish and the very small amount of milt that was obtained from most of the ripe males that were caught. A relatively high proportion of tripletail in the Mississippi Sound are found to be reproductively inactive even during the spawning season while spawning is presumed to occur offshore (Brown-Peterson and Franks, 2001). Collection of broodfish for seed preservation would be more effective if ripe males with large quantities of milt and high initial sperm motility were available. This will be difficult to achieve with wild tripletail as ripe fish are usually easier to capture in nearshore waters where sexual activity is more limited than offshore. Overcoming the inhibitions of spermatogenesis and spermiation discussed above in captivity would therefore be a precious step to develop captive spawning but also to allow collection and preservation of high quality gametes. 


\section{Early development of larvae}

The objective of this project section was to provide a first description of the development of tripletail larvae in captivity and develop a pilot protocol for larval and juvenile rearing in this species. One larval trial was performed using the fertilized eggs produced during the first induction experiment performed in 2010 (experiment 1 in section 1.2.1 described above). Tripletail spawning occurs offshore during the summer season, and larvae are usually found in surface waters (Ditty and Shaw 1994). This early life history is similar to that of the red snapper. We therefore employed a protocol similar to the red snapper larval rearing protocol routinely used in our laboratory (based on the original protocol described by Ogle and Lotz 2006) and based on early feeding using copepod nauplii.

\subsection{Materials and Methods}

Fertilized eggs for this experiment were obtained from the first tank-spawning trial performed in 2010. Approximately 74,000 fertilized eggs were produced during the spawning event recorded on $09 / 10 / 2010$. Eggs were transferred to four cylindroconical incubators connected to a recirculating seawater system and maintained under moderate aeration and a water turnover of $300 \mathrm{ml} \cdot \mathrm{min}^{-1}$. Salinity and temperature were $31.7 \mathrm{ppt}$ and $26.7^{\circ} \mathrm{C}$, respectively, and dissolved oxygen was $6.2 \mathrm{mg} . \mathrm{l}^{-1}$. Larvae were removed from incubators and counted on 09/11 approximately 24 hours post hatch and stocked evenly into two 1,500-L larviculture tanks. Detailed description of the larval culture system used in the study is available in Lemus et al. (2014).

Considering the low numbers of larvae and limited availability of copepod livefeeds, the tanks were filled with a half volume (700 1) and water was not recirculated in order to minimize the loss of copepod and maintain a high prey density. A low aeration was applied after observation of the behavior of the larvae escaping disturbances at the beginning of the trial. A continuous photophase was applied throughout the trial and light intensity at the water surface was between 180 and 260 lux.

Feeding was based on copepod Acartia tonsa nauplii. Initially A. tonsa eggs were added to the tanks (from 09/11 through 09/13), then nauplii were added as needed to maintain prey density. Prior to feeding, the amount of residual live food remaining in larval tanks was estimated by volumetric sampling and used as a guide for determining the amount of fresh enriched live food to be added. Copepod nauplii were present at a density of $0.5 / \mathrm{ml}$ on $09 / 12$ and densities higher than 1 nauplii/ml later on. Rotifers were added on 09/19 and 09/20.

Larvae were sampled on 09/11,09/14, 09/15, 09/16, and 09/20 and positioned under anesthesia on a glass slide using fine-tipped calipers and mounted onto a stereomicroscope (Meiji Techno RZ stereomicroscope) for measurement of Standard Length (SL), Head Length (HL), and Body Depth (BD). Biometric measurements were taken using the digital image analysis software (software and camera - ProgRes Capture 2.5, Jenoptik Germany). 


\subsection{Results}

Larvae tended to move to the lower part of the tank throughout the trial. Complete mortality was observed at 10 days post hatch. The vitellin reserves were almost completely resorbed at 1 day post hatch (only the oil globule remained). The eye was pigmented and the mouth was opened at $3 \mathrm{dph}$ which prompted the initiation of exogenous feeding at that date. Feeding was not observed but some of the larvae likely did initiate feeding considering that we were able to sample larvae until 09/20 (9 days post hatch, Figure 1). Growth in length seemed moderate during the period (Table 6) but the larvae grew in depth and developed a mouth and a compartmented digestive tract (Figure 1). A supra-occipital crest was observed as early as 3 days post hatch. At this time a pigmentation line was also visible along the dorsal part of the digestive tract.

Table 6. Mean \pm SD for Standard length (SL), Head length (HL) and Body depth (BD) recorded on cultured tripletail (Lobotes surinamensis) larvae

\begin{tabular}{|l|l|l|l|}
\hline Date & SL $(\mu \mathrm{m})$ & HL $(\% \mathrm{SL})$ & BD $(\% \mathrm{SL})$ \\
\hline $09 / 11$ & $2816 \pm 269(\mathrm{n}=4)$ & $0.16 \pm 0.01$ & $0.15 \pm 0.03$ \\
\hline $09 / 12$ & $2941 \pm 83(\mathrm{n}=3)$ & $0.13 \pm 0.003$ & 0.12 \\
\hline $09 / 14$ & $3036(\mathrm{n}=1)^{\star}$ & 0.18 & 0.15 \\
\hline $09 / 15$ & $2949 \pm 31(\mathrm{n}=3)^{\star}$ & $0.19 \pm 0.01$ & $0.19 \pm 0.01$ \\
\hline $09 / 16$ & $3286 \pm 6(n=2)^{\star}$ & $0.21 \pm 0.01$ & $0.20 \pm 0.01$ \\
\hline $09 / 20$ & $3575(\mathrm{n}=1)^{\star}$ & 0.29 & 0.30 \\
\hline
\end{tabular}

* Calibration of the length measurement could not be confirmed; results are provided as tentative and will require confirmation

\subsection{Discussion perspectives}

Fertilized eggs and hatched larvae were only available during the first trial implemented in fall 2010. More than 70,000 larvae were stocked in larval tanks but complete mortality was observed a few days post hatch suggesting that most larvae only transiently initiated feeding or did not initiate feeding at all. Tripletail larvae are usually collected in surface tows (Ditty and Shaw, 1994) suggesting that light intensity may be an important factor stimulating first feeding as was reported in other species with pelagic larvae (red snapper, J. Ogle, Personal communication; Saillant and Leclercq, Unpublished results; Copeland and Watanabe 2006). The relatively low light intensity employed in our trial may have been detrimental if high light intensity is required for tripletail early larvae. Thus, the role of the light intensity and spectrum would deserve to be explored in future studies.

Hydrodynamic conditions also have been shown to be critical to early survival and first feeding of marine species with pelagic larvae developed at GCRL (see e.g. different aeration levels required by Atlantic croaker and red snapper larvae, Saillant and Lemus Unpublished results) and may need to be explored in tripletail as well. Another potential issues lies in the quality of eggs produced by females. Most of the mortality was observed at the time of first feeding when vitellin reserves became exhausted. The quality and/or quantity or vitellin reserves may have been insufficient to supply the energy required during the transitional feeding period when larvae attempt to feed, and may have resulted in unsuccessful initiation of feeding and mortality. Egg quality and the survival potential of larvae past first feeding could be monitored using standardized methodologies employed in our laboratory for other species (Bardon et al. 2013) in future trials to determine the viability of larvae. Research on broodstock nutrition also 
would be useful in order to better understand requirements of maturing tripletail females and achieve high quality larvae for culture trials.

Finally, the present study provides information on the onset of the ontogeny of morphological characters that can be used in the identification of early tripletail larvae in the wild. The supra-occipital crest reported by Ditty and Shaw (1994) appears to form very early (visible as early as $3 \mathrm{dph}$ ) and could be used as an easy way to identify early larvae of that species. Further development of larviculture protocols will be precious to further describe larvae at different stages of development, and also to study the early life history and habitat requirements of tripletail.

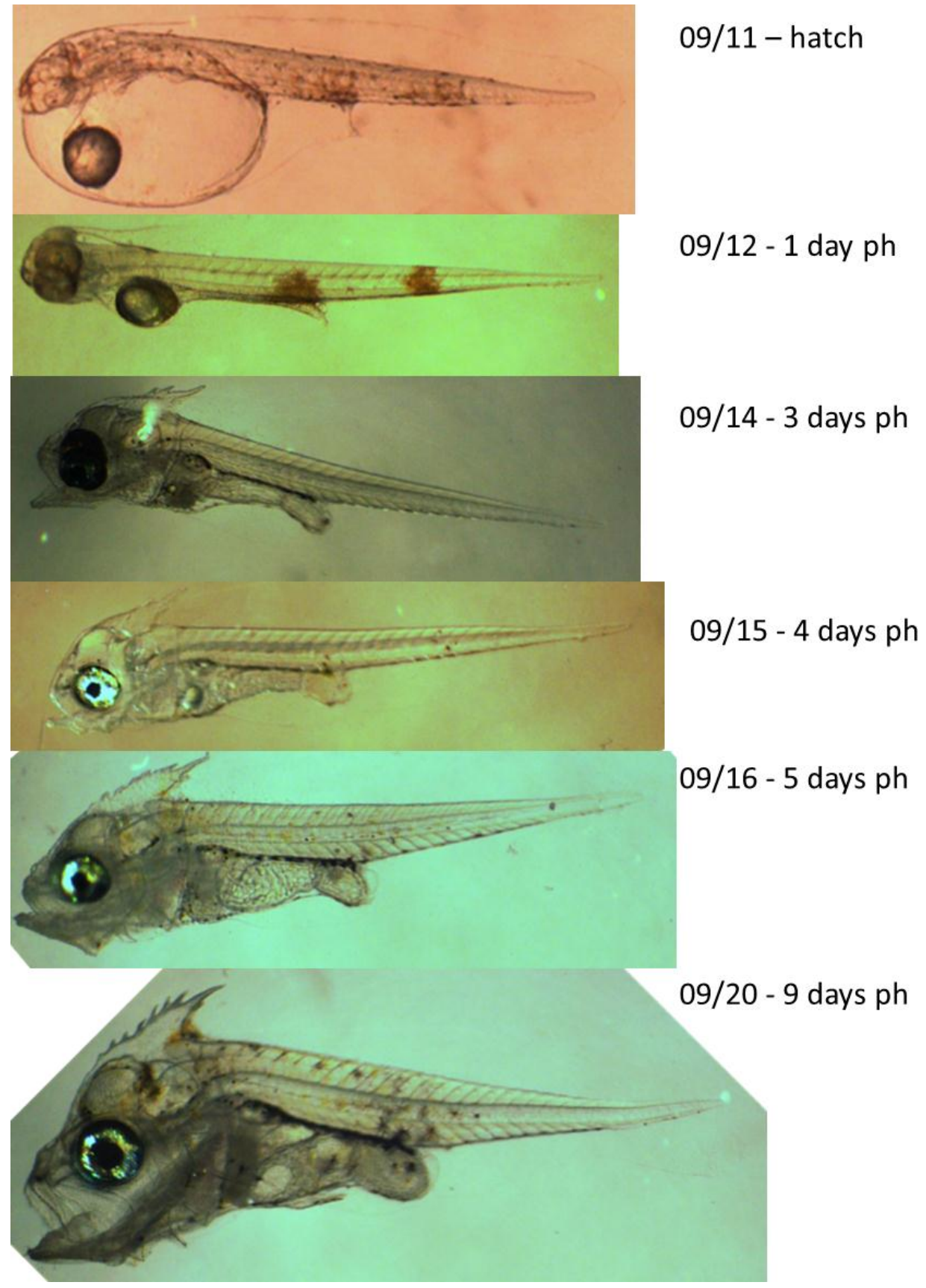

Figure 1. Larval development of cultured tripletail (Lobotes surinamensis) in culture conditions 


\section{Development of a non-lethal sexing method by measuring plasma levels of gonadal steroids}

\subsection{Rationale}

The studies of captive spawning conducted during this project and described in section 1 of this report revealed that sex identification is an important issue for tripletail aquaculture. Tripletails are only present in Mississippi coastal waters during the summer months and are usually available only in small numbers. It is therefore critical to identify the sex of candidate brooders to ensure that mating sets in spawning tanks will include both males and females. The importance of controlling the sex ratio to ensure pre-maturation of fish was further suggested by the results of spawning trials reported in section 1 with a complete lack of ovulation of females induced with gonadotropin (see results of experiment 3 in section 1.) when there was no male among the broodstock.

In several species, the sex of specimens caught during the course of the spawning season can be reliably identified by observing the aspect of the genital papilla or other secondary sexual character. In the absence of such characters, stimulating the spontaneous release of sperm by ripe males via gentle abdominal massage, or collecting ovarian biopsies in females using a catheter allow reliable sexing of several species during the spawning season. Unfortunately, although most tripletails are captured during the pre-spawning and spawning seasons (May to September, Brown-Peterson and Franks 2001) in Mississippi coastal waters, these sexing methods have proved largely ineffective or at least unreliable to date. The genital papilla is not sexually dimorphic and there is no other visible sexual character. Males usually do not emit sperm even when ripe and it is very difficult to obtain ovarian biopsies, especially if females are immature. While morphometric approaches might be worth deploying to evaluate if subtle morphologic differences occur between sexes, acquisition of sufficient sample sizes to establish and validate such a method is challenging in tripletail.

On another hand, gonadal sex steroid are expected to be differentially expressed in males and females reflecting the physiology of testes versus ovary. While some steroids such as testosterone are produced by both sexes (Nagahama, 1994), male fish produce a nonaromatisable androgen, the 11-Ketotestosterone $(11-\mathrm{KT})$ that is involved in spermatogenesis and is specific of the male (Fostier et al., 1983). In females in active vitellogenesis, the estrogen Estradiol-17 $\beta$ (E2) is produced in high quantities by the gonad and regulates the production of vitellogenin by the liver. Levels of E2 in females during that period are supposed to far exceed those observed in males making this hormone a potential indicator of phenotypic sex if measured in maturing females. Assays of these two hormones based on plasma samples can be performed using competitive immune assays that are readily available and the measurement of these sex steroids can therefore be used as a potential non-lethal method for the determination of the sex of candidate brooders (Devlin and Nagahama 2002). This approach has indeed been recently deployed successfully to sex identification in other fish species (e.g. Chu-Koo et al. 2008). Our objectives in this project section, were to test and validate Enzyme Immuno Assays for the measurement of plasma levels of 11-KT and E2 in tripletail, and initiate a database of circulating levels of these two hormones in males and females tripletail collected in Mississippi coastal waters during the spawning season, in order to evaluate the potential of these two hormones, alone or in combination, for sex identification in tripletail. 


\subsection{Materials and methods}

\subsubsection{Sample collection}

Samples were obtained during two collection trips targeting wild adult tripletail during the course of the 2013 summer spawning season. Three males were sampled on June 132013 and their phenotypic sex was formally identified upon arrival at the laboratory when sperm was extracted from gonads after dissection (see section 1.1.4 and 1.2.2). Another 3 blood samples were obtained on July 22. During this second collection trip, females and one individual whose sex could not be determined were caught. Blood was drawn immediately at capture using heparinized syringes $(10 \mathrm{mg} / \mathrm{ml})$ and kept on ice during transfer to GCRL. Upon arrival to the laboratory (within 3 hours of capture), samples were transferred to microtubes and centrifuged $15 \mathrm{~min}$ at $1,200 \mathrm{~g}$ and $4{ }^{\circ} \mathrm{C}$. Plasma was transferred to a clean microtube and stored at $-80{ }^{\circ} \mathrm{C}$ until Enzyme Immuno Assays.

\subsubsection{1-Ketotestosterone and Estradiol-17 $\beta$ assays}

11-Ketotestosterone (11KT) and Estradiol-17 $\beta$ (E2) were assayed using competitive Enzyme Immuno Assays (EIA, Pradelles et al. 1985). The assay quantifies the concentration of steroid (11-KT or E2) in samples by measuring the displacement of a tracer (11-KTAcethylcholinesterase or E2- Acethylcholinesterase) bound to a specific antiserum (anti 11-KT or anti-E2).

Prior to assay, 11-KT was extracted 3 times from the plasma samples with Ethyl acetatehexane (50:50). The solvent was evaporated at $30{ }^{\circ} \mathrm{C}$ using a vacuum concentrator and the extract was resuspended in EIA buffer (Cayman chemicals) for assay. Similarly, E2 was extracted 4 times from the plasma samples with methylene chloride and the solvent evaporated prior to reconstitution of samples in EIA buffer.

Assays for both hormones were performed using EIA kits (Cayman chemicals) according to instructions from the manufacturer. Incubation of the hormone with tracer and antiserum was performed for $2 \mathrm{~h} 00$ for the $11-\mathrm{KT}$ assay and $1 \mathrm{~h}$ for the E2 assay. Plates were developed for $2 \mathrm{~h}$ and $1 \mathrm{~h} 30$ for the $11-\mathrm{KT}$ and E2 assays, respectively and absorbance was read at $410 \mathrm{~nm}$ in a Synergy II plate reader (Biotek). All wells were blanked and standardized for non-specific binding. The maximum tracer bound (B0) was measured by incubating the antiserum-tracer reaction with no competing unlabeled hormone, and the absorbance of each samples (B) was expressed as the percentage of sample bound to the maximum bound (B/B0).

\subsubsection{Data analysis}

Data were logit transformed using equation 1

$$
\log i t(B / B 0)=\ln \left[\frac{\left(\frac{B}{B_{0}}\right)}{\left(1-\frac{B}{B_{0}}\right)}\right]
$$

Equation 1 
The logit function is expected to display a linear relationship to the logarithm of hormone concentration when $\% \mathrm{~B} / \mathrm{B} 0$ is between 20 and $80 \%$. A series of standards of known hormone concentration was assayed along with the samples and used to establish a prediction equation for each assay after testing for the linear relationship between logit(B/B0) and the logarithm of hormone concentration $(\ln (\mathrm{c}))$. The prediction equation was used to determine the hormone concentration in the tripletail samples under study.

The validity of the assay for measuring 11-KT or E2 was determined by testing the parallelism of the regression between logit(B/B0) and $\ln (\mathrm{c})$ determined using hormone standards and that of $\operatorname{logit}(\mathrm{B} / \mathrm{B} 0)$ determined from serial dilutions of test tripletail samples. The intra and inter-assay coefficient of variations for both assays were determined at various hormone concentrations based on intra assay replicates ( 2 replicates per concentration) run in two separate assays.

\subsection{Results}

\subsubsection{Assay validation for tripletail}

The detection limits of the 11-KT and E2 assays were $1.7 \mathrm{pg} \cdot \mathrm{ml}^{-1}$ and $16.9 \mathrm{pg} \cdot \mathrm{ml}^{-1}$ respectively. The intra and inter-assay coefficient of variation averaged 14.0 and $19.1 \%$ in the linear range of the standard curve for the $11-\mathrm{KT}$ assay and 8.2 and $10.5 \%$ for the E2 assay (Table 7).

Table 7. Intra and inter assay variation for the 11-Ketotestosterone and Estradiol-17 $\beta$ Enzyme Immunoassays.

\begin{tabular}{|l|l|l|}
\hline $11-$ Ketotestosterone & \multicolumn{2}{l|}{} \\
\hline Concentration $(\mathrm{pg} / \mathrm{ml})$ & $\% \mathrm{CV}^{*}$ for intra-assay variation & $\% \mathrm{CV}^{*}$ for inter-assay variation \\
\hline 100 & 27.3 & - \\
\hline 50 & 7.73 & 25.8 \\
\hline 25 & 8.4 & 0.3 \\
\hline 12.5 & 15.5 & 31.2 \\
\hline 6.25 & 5.2 & 24.9 \\
\hline 3.13 & 20.0 & 13.2 \\
\hline Average & 14.0 & 19.1 \\
\hline Estradiol-17ß & \multicolumn{2}{|l|}{} \\
\hline Concentration $(\mathrm{pg} / \mathrm{ml})$ & \multicolumn{2}{|l|}{} \\
\hline 4000 & 8.1 & 12.3 \\
\hline 1600 & 7.4 & 10.6 \\
\hline 640 & 1.6 & 1.3 \\
\hline 256 & 8.2 & 10.7 \\
\hline 102.4 & 13.3 & 7.9 \\
\hline 41 & 10.7 & - \\
\hline 16.4 & - & 15.3 \\
\hline Average & 8.2 & 10.5 \\
\hline$* \%$ CV represents the variation in concentration as determined using the prediction equation.
\end{tabular}


The regression analysis of the standard curve indicated fit to the linear model between logit (B/B0) and $\ln (\mathrm{c})\left(R^{2}=0.994\right.$ for $11-\mathrm{KT}, R^{2}=0.987$ for E2). Tests of parallelism indicated that the slope of the 11-KT standard curve did not differ significantly from that obtained during serial dilution of the tripletail test-serum (Figure $2, F=0.31, d f_{\text {among slopes }}=1, d f_{\text {error }}=6, P=0.598$ ). Parallelism could not be tested for the E2 assay due to limited amount of plasma available and the low levels of hormones in available samples. The three serial dilutions performed suggest that the serial dilution of plasma samples parallel the standard curve (Figure 3)

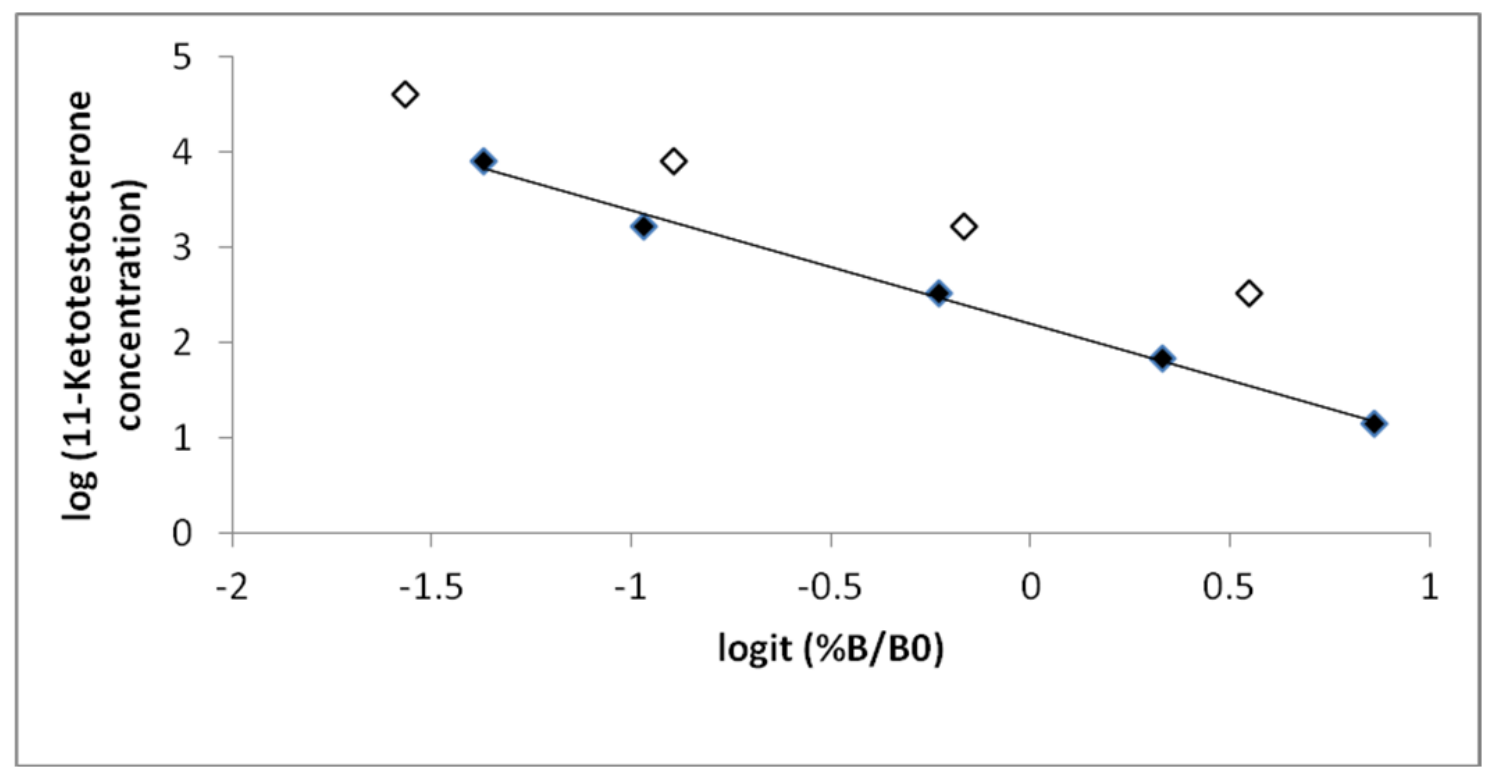

Figure 2. Linearity plot relating the logarithm of the concentration of 11-Ketotestosterone to the $\operatorname{logit}$ of $\% \mathrm{~B} / \mathrm{B} 0 . \diamond: 11-$ Ketotestosterone standard $\diamond$ : Serial dilutions of tripletail test serum extract.

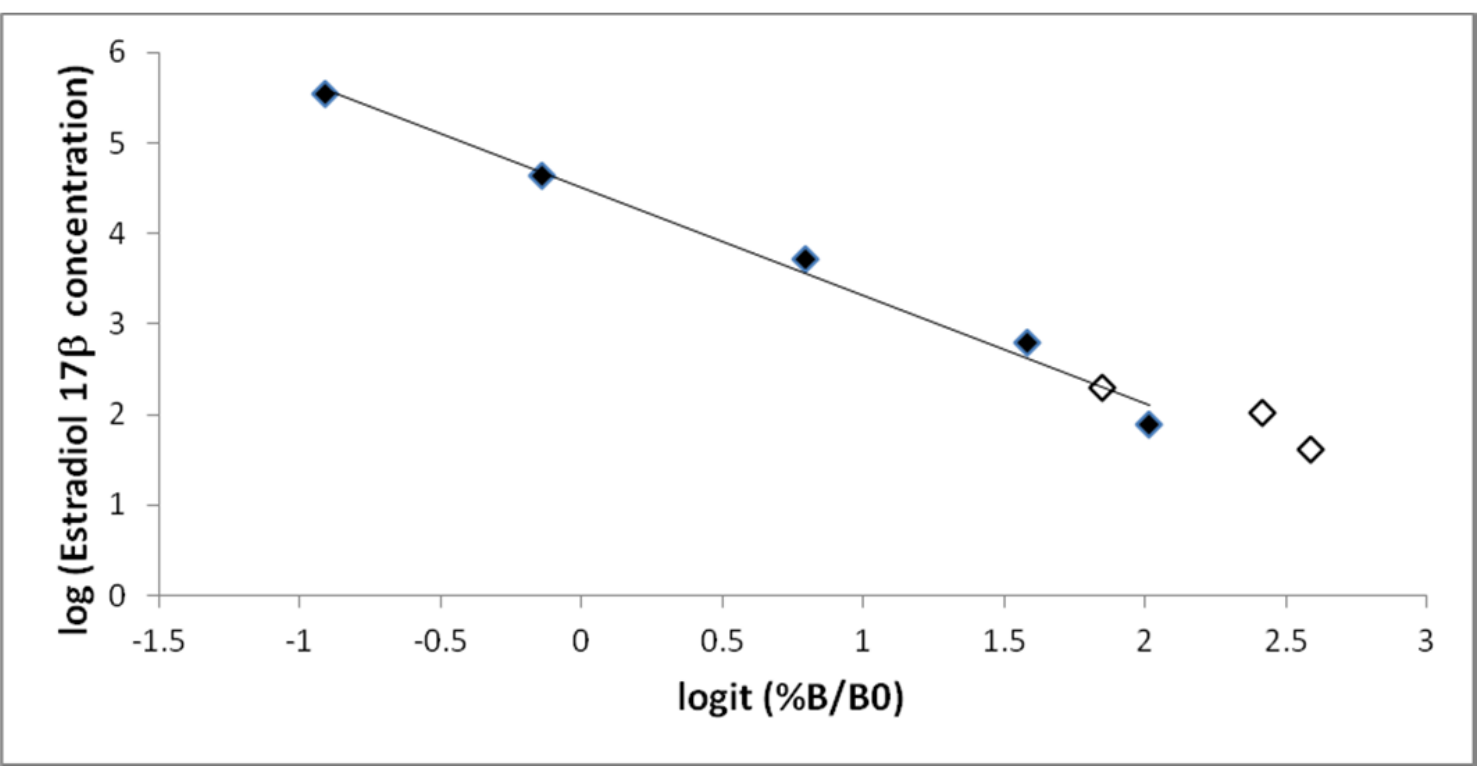

Figure 3. Linearity plot relating the logarithm of the concentration of Estradiol-17 $\beta$ to the logit of $\% \mathrm{~B} / \mathrm{B} 0$ (see text for details). $\diamond$ : Estradiol-17 $\beta$ standard $\diamond$ : Serial dilutions of tripletail test serum extract. 


\subsubsection{Levels of 11-KT and E2 in plasma samples from wild caught tripletail during the spawning season}

The specimens collected on June 13 were examined in the laboratory and sexed as males by visual examination of the gonads after dissection. Milt was observed in testes although in small quantity and gonads were undeveloped. The sex of one of the three fish collected on July 22 could not be identified while the remaining fish were females but all immature with no signs of active vitellogenesis.

Plasma levels of 11-Ketotestosterone and Estradiol-17 $\beta$ in samples from wild caught tripletails are presented in figures 4 and 5. Levels in confirmed males were higher than $50 \mathrm{pg} / \mathrm{ml}$. One of the three fish caught on July $22(\mathrm{u} / \mathrm{f}-1)$ had levels typicals of the confirmed males and the remaining two fish $(\mathrm{u} / \mathrm{f}-2$ and 3 , presumably females) had measurements close to the detection threshold of the assay.

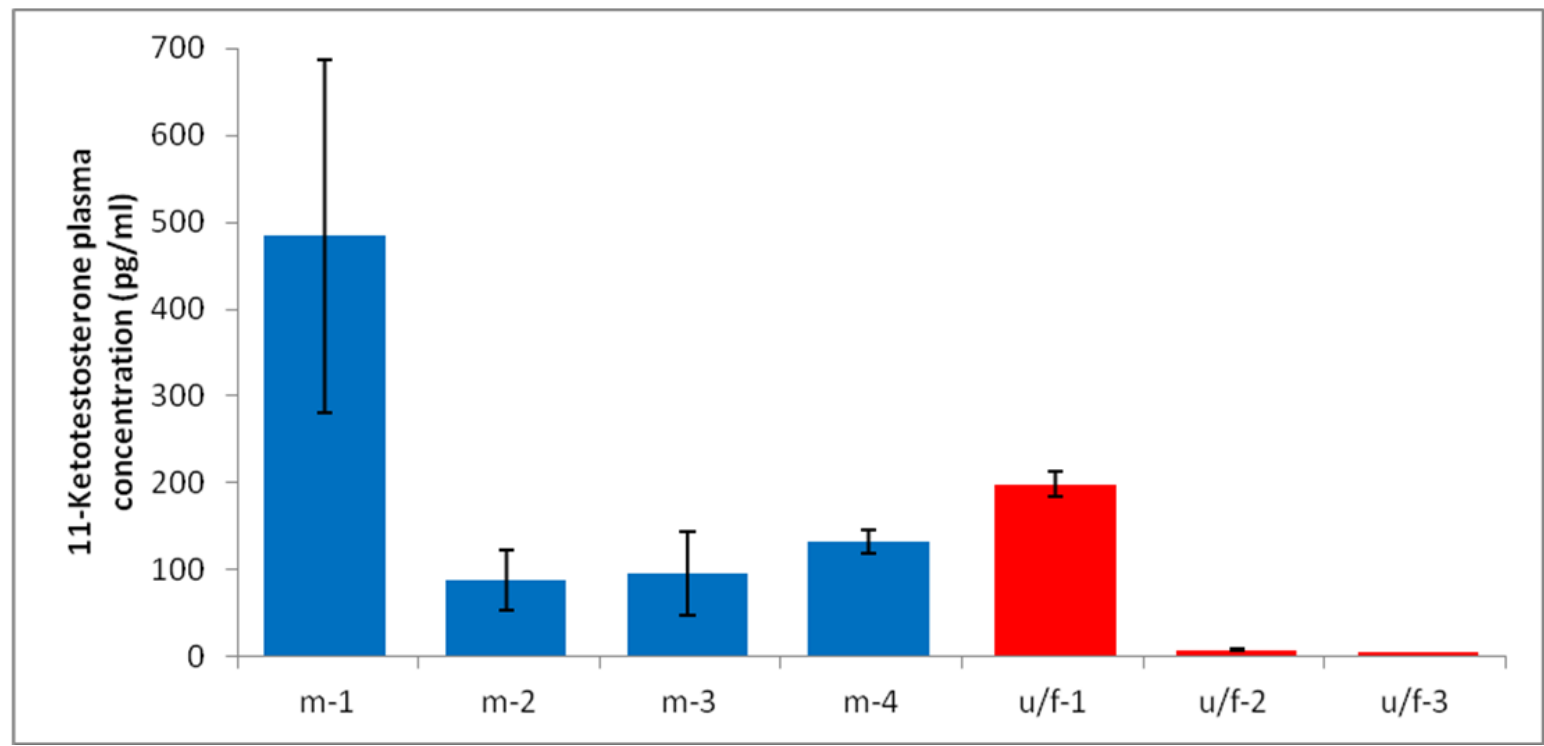

Figure 4. Plasma levels of 11-Ketotestosterone recorded in caught males ( $(\square)$ and Undetermined and females ( $\square$ ) Lobotes surinamensis caught during the 2013 summer season.

Levels of E2 were between 28 and $55 \mathrm{pg} / \mathrm{ml}$ for all fish assayed. There appears to be no clear differences between sexes (Figure 5). 


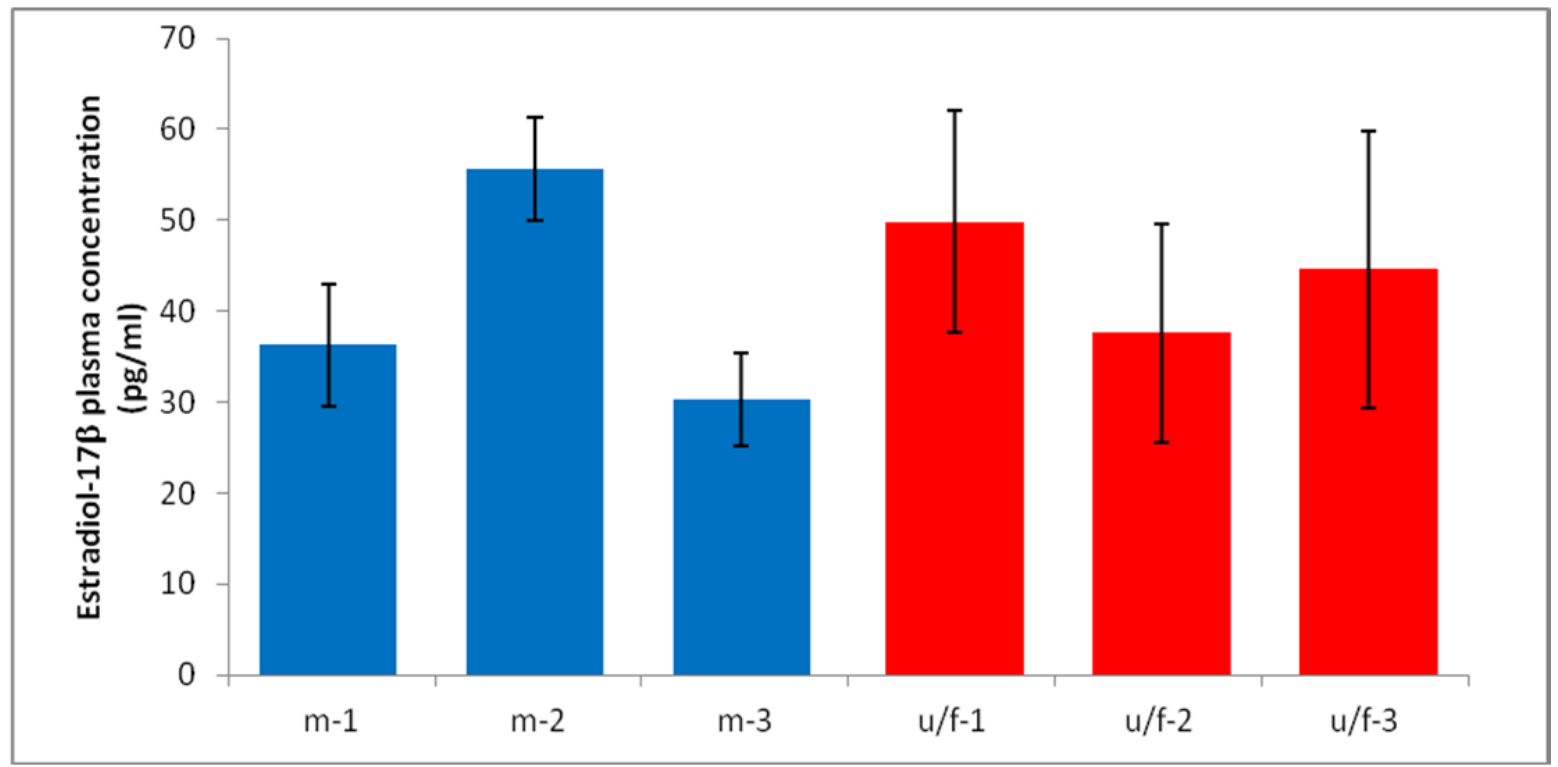

Figure 5. Plasma levels of Estradiol-17 $\beta$ recorded in wild caught males ( $\square$ ) and Undetermined and females ( $\square$ ) Lobotes surinamensis caught during the 2013 summer season.

\subsection{Discussion}

In this project, section assays for two gonadal steroids were characterized in tripletail. The 11-Ketotestosterone assay could be validated using serial dilutions of the plasma samples from males showing high concentration of this hormone. The Estradiol assay could not be validated formally using serial dilutions due to the low amount of plasma available and the low concentration of E2 in the plasma of tested females. However, the dilutions that could be measured suggest that parallelism is likely met for this hormone as well.

Although the sex of one of the individuals collected in July could not be established in the field, the results obtained using the 11-KT assay are encouraging regarding the prospect of identifying sexes using levels of this hormone. The putative females had levels at or below the detection threshold even when samples were run undiluted and thus appear to be discriminated from the males that all show significant levels of $11-\mathrm{KT}$. This result is consistent with finding in other species that indicate that $11-\mathrm{KT}$, a non- aromatisable androgen, is produced specifically by the male (Fostier et al. 1983) and one of the key gonadal steroid involved in spermatogenesis. Females are therefore not expected to produce this hormone in significant levels.

In contrast, E2 levels were similar (and low but detectable) in all individual males and females. Estradiol is produced in high amount by females during vitellogenesis and, at that stage, levels are expected to differ substantially from those in males (Chu-Koo et al. 2009). The females that were sampled were immature with no sign of active vitellogenesis which explains the low levels of E2 recorded. These results indicate that the usefulness of E2 for sexing of tripletail candidate brooders caught in the Mississippi sound is moderate. Indeed, as discussed earlier, a large proportion of the fish brought alive to the laboratory are expected to be immature or sexually inactive. In that situation, the results above suggest that levels in females may be low and indistinguishable from those in males. E2 might be helpful for sexing vitellogenic females if some are caught, but mature females are also the ones that can usually be sexed easily using a catheter and the hormonal confirmation of sex identifications is less critical in those cases. On 
another hand, 11-KT levels were very low in females and even the young males with low levels of spermatogenetic activity caught during the present study appeared to show substantially higher levels than the females. In addition, the $11-\mathrm{KT}$ assay is very sensitive $(1.7 \mathrm{pg} / \mathrm{ml})$ meaning that most samples can (/need to) be diluted prior to assay which will be very useful in practice if only small amounts of blood can be collected in the field. A priority for future research will be to collect additional samples to establish the accuracy and reliability of sexing using this hormone.

\section{General conclusions and recommendations}

During this project, investigations were conducted in the area of spawning, culture of early stages, and sexing of tripletail candidate broodstock. The study showed that tripletail adults can be easily brought into captivity and conditioned for spawning. Spawning did not occur spontaneously, but final maturation of gametes was reliably achieved using hormonal induction with gonadotropin releasing hormone implants followed by tank spawning. The general lack of fertilization in all attempts suggests that disruptions of sperm production by males and/or disruption of the interaction and spawning behaviors occurred in captive conditions. In addition, results of hormonal induction trials when no males had been present in spawning tanks during the course of the spawning season also suggest that the presence of males is necessary for successful pre-maturation of females. Investigation of husbandry issues potentially involved in the inhibition of gamete maturation and spawning of captive tripletail will therefore be a priority for future research. Experiments manipulating fish density and/or sex ratio during the maturation and spawning seasons would likely provide useful information. Hormonal induction using antidopaminergic, potentially alleviating the effect of stress-related inhibitions, may also be worth exploring in particular in order to increase the fertilization rates of spawns.

The attempt to culture larvae was unsuccessful with complete mortality observed shortly after first feeding. Several potential factors including environmental conditions in larval tanks (light, hydrodynamics) and nutritional factors will need to be explored in order to better match culture conditions with the requirements of tripletail larvae. Some hypotheses can be formulated for future trials accounting for the conditions encountered by tripletail larvae in the wild and successful protocols developed in other species with pelagic larvae.

Finally a major difficulty was encountered when attempting to identify the sex of candidate brooders using non-lethal approaches. The evaluation of measurements of plasma levels of 11Ketotestosterone as a non-lethal sexing method conducted during the project was encouraging. Only a small amount of blood would need to be collected at capture to run this assay and results obtained on the samples collected in 2013 are promising. This method will need to be evaluated using a larger sample of male and female tripletail at different sexual maturity stage to establish the accuracy and reliability of the method.

\section{References}

Bardon-Albaret, A., N.J. Brown-Peterson, J.T. Lemus, A. Apeitos, and E. Saillant. A histological study of gametogenesis of red snapper Lutjanus campechanus in captivity. Aquaculture Research, In Press. 
Bardon, A., Saillant, E. 2013. Investigations on egg and larvae quality of red snapper Lutjanus campechanu. World Aquaculture Society conference, Nashville, TN, February 21-25 2013

Brown-Peterson, N.J., and J.S. Franks. 2001. Aspects of the reproductive biology of tripletail, Lobotes surinamensis, in the northern Gulf of Mexico. Proc. Gulf Carib. Fish. Inst. 52:586-597.

Chu-Koo, F., R. Dugué, M. Alván Aguilar, A. Casanova Daza, F. Alcántara Bocanegra, C. Chávez Veintemilla, F. Duponchelle, J.F. Renno, S. Tello, J. Nuñez. 2009. Gender determination in the Paiche or Pirarucu (Arapaima gigas) using plasma vitellogenin, 17 $\beta$-estradiol, and 11ketotestosterone levels. Fish Physiol. Biochem. 35:125-136.

Copeland, K.A., W.O. Watanabe. 2006. Light intensity effects on early life stages of black sea bass, Centropristis striata (Linnaeus 1758). Aquaculture Research 37: 1458-1463.

Devlin, R.H., Y. Nagahama. 2002. Sex determination and sex differentiation in fish: an overview of genetic, physiological, and environmental influences. Aquaculture 208, 191-364.

Ditty, J.G., and R.F. Shaw. 1994. Larval development of tripletail, Lobotes surinamensis (Pisces: LobotidaeJ, and their spatial and temporal distribution in the northern Gulf of Mexico. Fish. Bull. 92:33-45.

Fostier, A., B. Jalabert, R. Billard, B. Breton. 1983. The gonadal steroids. In: Hoar WS, Randall DJ, Donaldson EM (eds) Fish physiology. Academic Press, New York, pp 277-372

Franks, J.S., J.T. Ogle, J. Read Hendon, D.N. Barnes, and L.C. Nicholson. 2001. Growth of captive juvenile tripletail Lobotes surinamensis. Gulf Carib. Res. 13:75-78.

Lemus, J.T., B.L. Sarkisian, M.S. Lee, A. Bardon-Albaret, and E. Saillant. 2014. A First Demonstration of Intensive-Type Larviculture of Atlantic croaker Micropogonias undulates. North American Journal of Aquaculture 76:45-54.

Mylonas, C.C., B.M. Richardson, S.P. Minkinnen, and Y. Zohar. 1995. Induced spawning of American shad (Alosa sapidissima) using sustained administration of gonadotropin-releasing hormone analog (GnRHa). J. World Aquac. Soc. 26: 39-50.

Mylonas, C.C., L.C. Woods III, P. Thomas, and Y. Zohar. 1998. Endocrine profiles of female striped bass (Morone saxatilis) in captivity, during post-vitellogenesis and induction of final oocyte maturation via controlled-release GnRHa-delivery systems. Gen. Comp. Endocrinol. 110: 276-289.

Mylonas, C.C., and Y. Zohar. 2008. Controlling reproduction in aquaculture. In: "New Technologies in Aquaculture: Improving Production efficiency, Quality and Environmental Management." (Gavin Burnel and Geoff Allen, eds.). Woodhead Publishing Ltd, Cambridge, UK.

Nagahama, Y. 1994. Endocrine regulation of gametogenesis in fish. Int. J. Dev. Biol. 38: 217229. 
Pradelles, P., J. Grassi, and J. Maclouf. 1985. Enzyme immunoassays of eicosanoids using acetylcholinesterase as label: An alternative to radioimmunoassays. Anal. Chem. 57:1170-1173.

Ogle, J., and J.M. Lotz. 2006. Characterization of an experimental indoor larval production system for red snapper. N. Am. J. Aquacult. 68:86-91.

Wang, J., M. Hu, W. Wang, X. Liu, S.G. Cheung, P.K.S. Shin, and L. Song. 2009. Effects of GnRHa (D-Ala6, Pro9-NEt) combined with domperidone on ovulation induction in wild loach Misgurnus anguillicaudatus. Aquaculture 291:136-139.

Zohar Y., A. Goren, M. Tosky, G. Pagelson, D. Leibovitz, and Y. Koch. 1989. The bioactivity of gonadotropin-releasing hormones and its regulation in the gilthead seabream, Sparus aurata: in vivo and in vitro studies. Fish. Physiol. Biochem. 7: 59-67.

Zohar Y., A. Goren, M. Fridkin, E. Elhanati, and Y. Koch. 1990. Degradation of gonadotropin releasing hormone in the gilthead seabream, Sparus aurata: II. Cleavage of native salmon GnRH, mammalian LHRH and their analogs in the pituitary, kidney, and liver. Gen. Comp. Endocrinol. 79: 306-319.

Zohar Y. 1996. New approaches for the manipulation of ovulation and spawning in farmed fish. Bull. Natl. Res. Inst. Aquacult. Suppl. 2: 43-47.

Zohar Y., C.C. Mylonas. 2001. Endocrine manipulations of spawning in farmed fish: from hormones to genes. Aquaculture 197: 99-136.

Appendix 1. Hormonal induction with hCG (Experiment 3)

Handling of fish under anesthesia a: transfer from the tank to the operation table b, c: Biopsy collection using a catheter d: injection of hCG hormonal treatment e: Tripletail in aquarium for observation following hormonal induction with $\mathrm{hCG}$

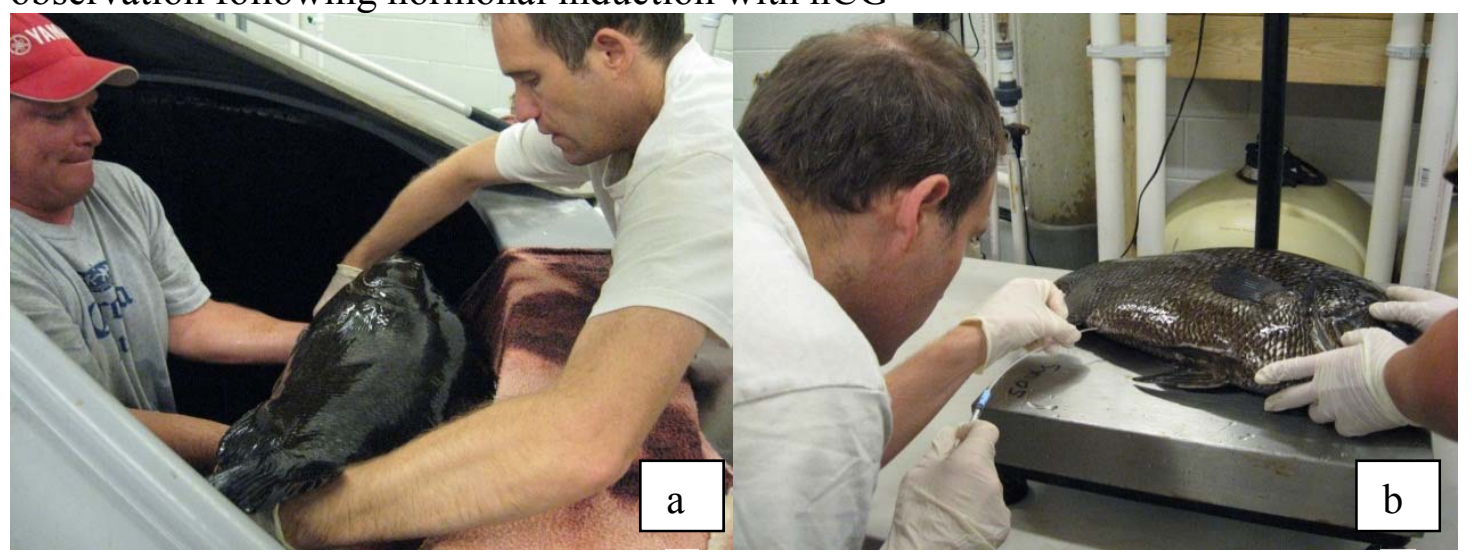



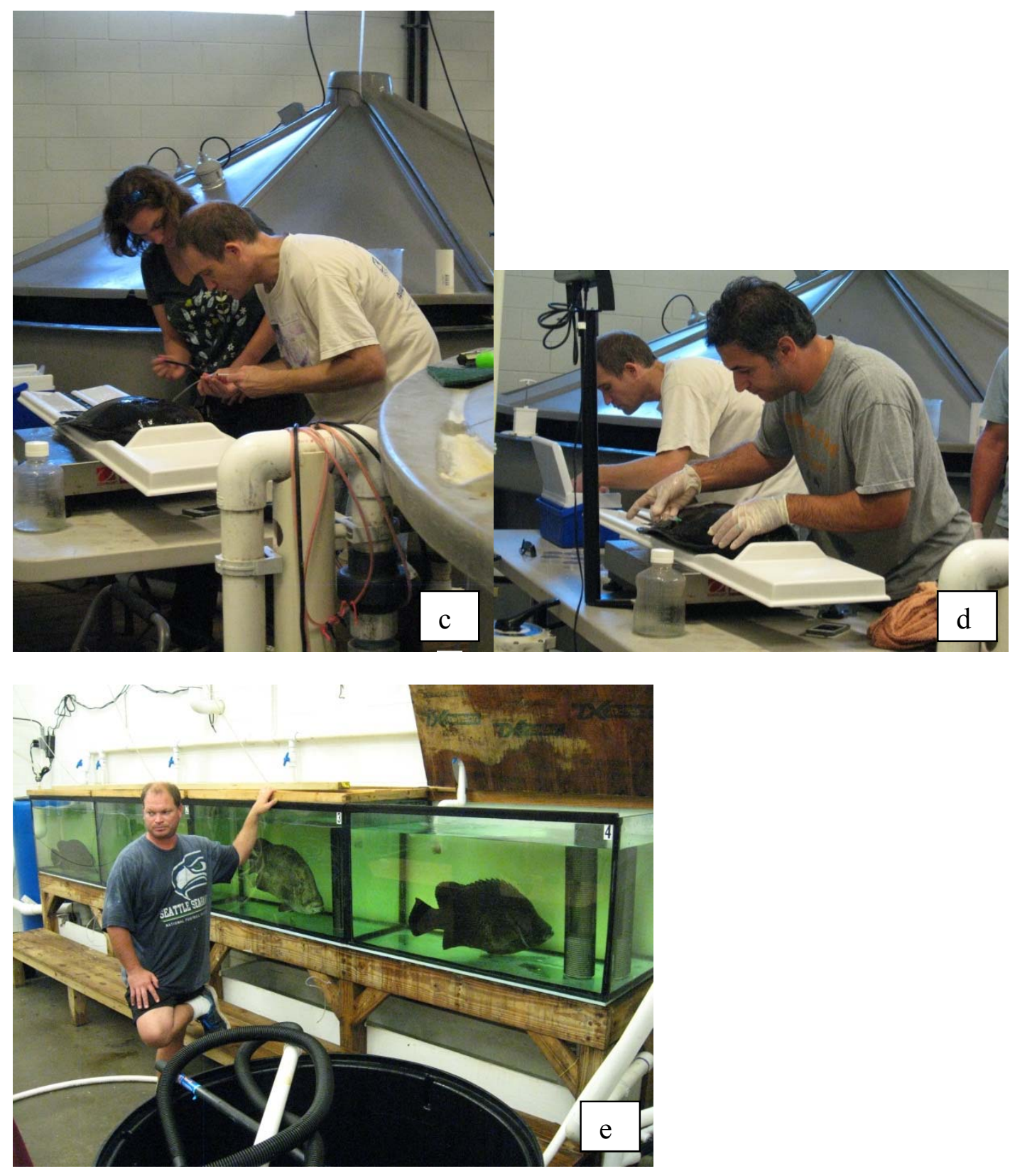
Appendix 2. Sperm collection by pipetting for cryo-preservation

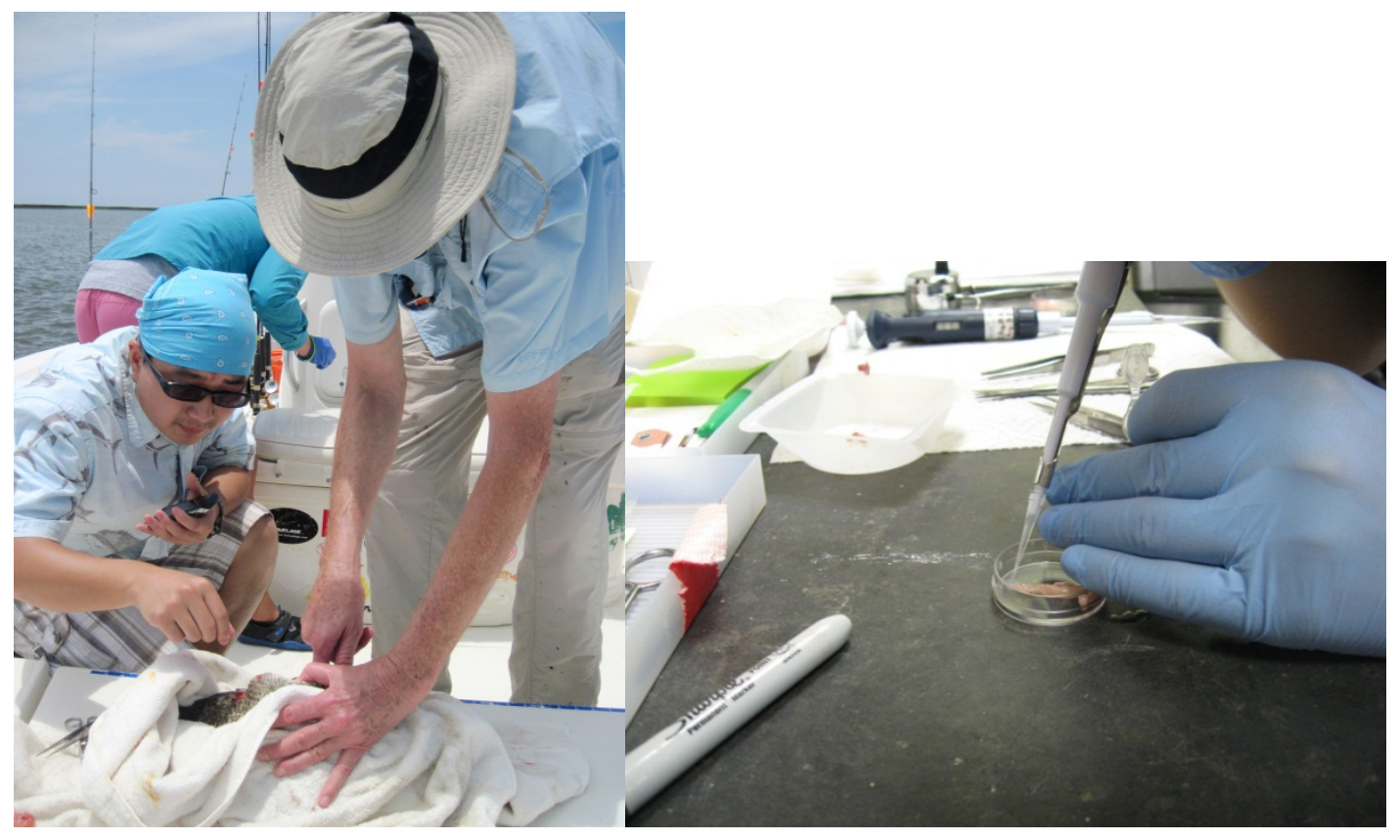


Appendix 3. Collection of blood samples for gonadal steroid assays

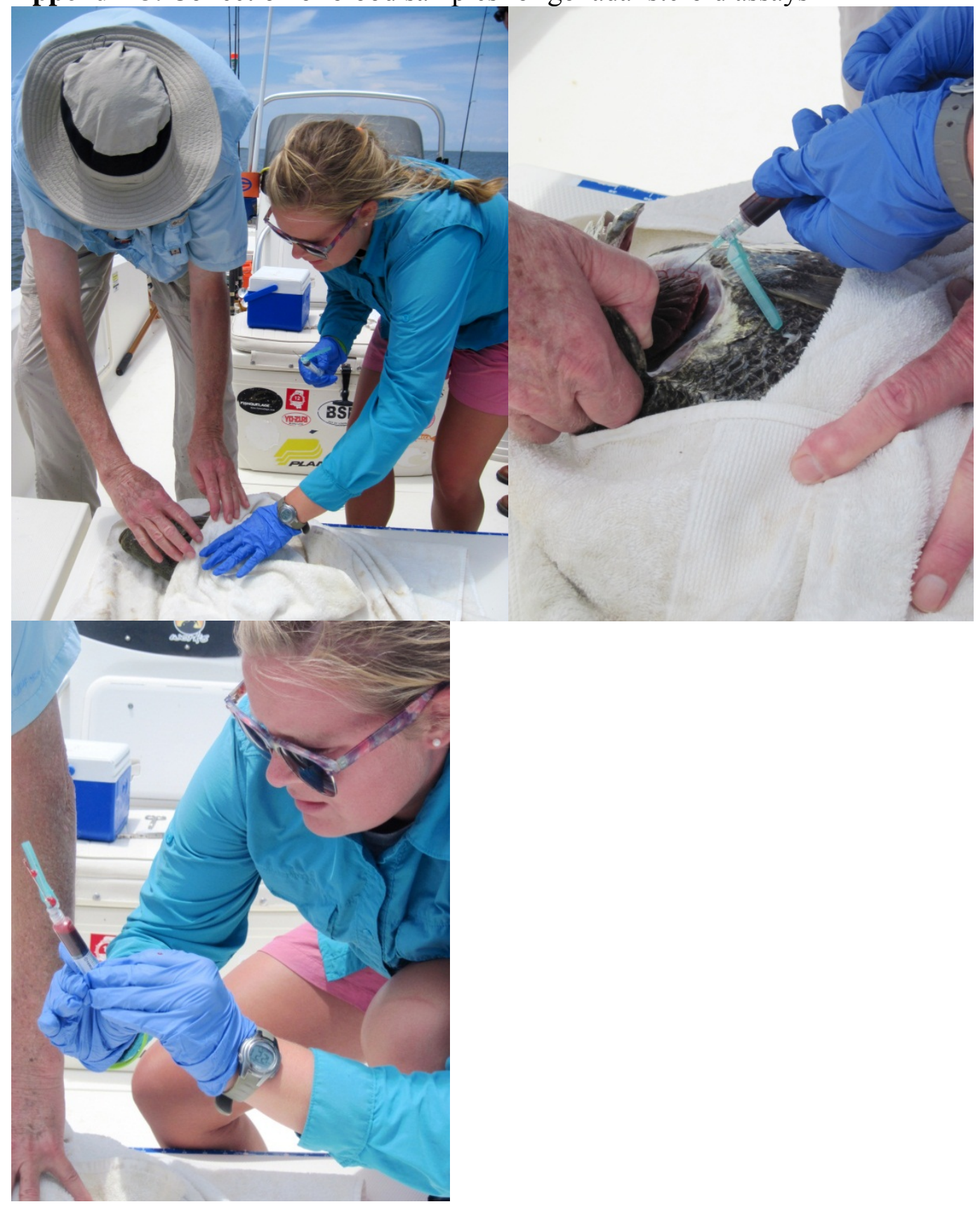

